\title{
Vibrotactile evaluation: Osseointegrated versus socket-suspended transfemoral prostheses
}

\author{
Eva Häggström, CPO; ${ }^{1-2 *}$ Kerstin Hagberg, PT, PhD; ${ }^{1-2}$ Björn Rydevik, MD, PhD; ${ }^{2}$ Rickard Brånemark, MD, PhD $^{2}$ \\ Departments of ${ }^{1}$ Prosthetics and Orthotics, and ${ }^{2}$ Orthopaedics, University of Gothenburg, Sahlgrenska University \\ Hospital, Gothenburg, Sweden
}

\begin{abstract}
This study investigated detection thresholds of vibrometric stimuli in patients with transfemoral amputation supplied with osseointegrated (OI) and socket-suspended prostheses. It included 17 patients tested preoperatively with socket-suspended prostheses and after 2 yr with OI prostheses and a control group $(n=17)$ using socket-suspended prostheses, evaluated once. Assessments on the prosthetic and intact feet were conducted at six frequencies $(8,16,32,64,125$, and $250 \mathrm{~Hz}$ ). Furthermore, measurements were conducted to investigate how vibrometric signals are transmitted through a test prosthesis. The results showed that the OI group had improved ability to detect vibrations through the prosthesis at $125 \mathrm{~Hz}(p=$ 0.01 ) at follow-up compared with the preoperative measurement. Compared with the control group, the OI group at follow-up had better ability to detect high frequency vibrations through the prosthesis (125 Hz, $p=0.02 ; 250 \mathrm{~Hz}, p=0.03$ ). The vibrometric signal transmitted through the test prosthesis was reduced at 8,125 , and $250 \mathrm{~Hz}$ but was amplified at 16, 32, and $64 \mathrm{~Hz}$. Differences between the OI and the control groups were found in the highest frequencies in which the test prosthesis showed reduction of the vibrometric signal. The study provides insight into the mechanisms of vibration transmission between the exterior and bone-anchored as well as socketsuspended amputation prostheses.
\end{abstract}

Key words: artificial limb, osseointegration, osseoperception, prosthesis, prosthetic foot, prosthetic knee, sensibility test, transfemoral amputation, vibrometric measurement, vibrotactile sensibility.

\section{INTRODUCTION}

Osseointegration for bone-anchorage of prostheses has been used in various prosthetic applications [1-3]. The most common is in dental care [4-5], and other attachments are in facial reconstructions [6-7] and hearing aids [8]. Today, osseointegration is also used in boneanchorage of external prostheses as an alternative to conventional socket-suspended prostheses for patients with limb amputations [1,9-11].

Patients using such osseointegrated (OI) prostheses have reported an improved ability to identify various sensations through their artificial limb [12-15], a phenomenon called osseoperception. Osseoperception has also been identified regarding the benefit of improved sensory feedback for bite force and oral function in patients with OI implants in the edentulous jaw $[13,16]$. Later work has further established the importance of osseoperception

\footnotetext{
Abbreviations: CGRP = calcitonin gene-related peptide, ICC = intraclass correlation coefficient, OI = osseointegrated, QST = quantitative sensory testing, TFA = transfemoral amputation.

*Address all correspondence to Eva Häggström, CPO; Department of Prosthetics and Orthotics, University of Gothenburg, Sahlgrenska University Hospital, Falkenbergsgatan 3, SE 41285 Gothenburg, Sweden; +46 (0) 31 343 8126; fax: +46 31408162 .

Email: eva.haggstrom@vgregion.se

http://dx.doi.org/10.1682/JRRD.2012.08.0135
} 
in patients with dental implants [17-18]. The term osseoperception has been stated to imply "the mechanosensibility associated with osseointegrated implant rehabilitation," further defined as "(i) the sensation arising from mechanical stimulation of a bone-anchored prosthesis, transduced by mechanoreceptors that may include those located in muscle, joint, mucosal, cutaneous and periosteal tissues, together with (ii) a change in central neural processing in maintaining sensorimotor function" [13].

Clinical observations have shown that patients can experience and identify various types of mechanical loading through OI implants. This suggests that a neurophysiological peripheral feedback pathway can be partly restored [16,19-20]. Such an assumption is supported by findings showing that two types of stimulation (pressure and strokes by a toothbrush) of an OI thumb prosthesis resulted in cortical activation on both sides of the somatosensory cortex, using functional magnetic resonance imaging of the brain [21]. Ysander et al. found an increase of calcitonin gene-related peptide (CGRP), a neuropeptide, around OI implants in an animal experimental study [22]. The increase of CGRP indicates that there might be an enhanced innervation of bone tissue around OI implants. However, the underlying mechanisms of the phenomenon of osseoperception are incompletely understood and the clinical effect of improved osseoperception in patients with limb amputations has not been fully explored.

Through different kinds of stimuli, e.g., light touch, thermal, vibration, or pain, sensibility can be measured. To evaluate sensibility, quantitative sensory testing (QST) has frequently been used in different clinical, epidemiologic, and research studies [23]. There are various QST methods, such as a simple patient answer of yes or no whether stimuli could be identified [24], choice between one out of two time periods that include stimuli [25], or when the patient is asked to press a button when a vibration stimuli is perceived and to press again when the stimulus disappears (the method of limits) [26]. Sensibility studies using vibration as stimuli have shown that mechanoreceptors in the skin can detect vibration frequencies between 0.4 and $800 \mathrm{~Hz}$ [27]. However, most published clinical data are from studies on patients with various type of neuropathic conditions [28-29], and in those studies, vibration frequencies between 20 and 250 $\mathrm{Hz}$ have been used as stimuli [28-30]. In patients with transfemoral amputation (TFA), testing sensation in terms of vibration seems to be one natural choice since vibration is one type of stimuli the patient hypothetically can experience when the prosthetic foot strikes the ground. At heel strike, the prosthetic knee joint should be in an extended position to make it safe to move the nondisabled limb forward [31-33]. Improved ability to detect vibration at heel strike could therefore mean safer walking for this group of patients.

The first study attempting to learn more about osseoperception and vibrations transmitted through the OI fixation in persons with amputation was initiated by Rydevik et al. [12]. A type of Békésy instrument for measuring vibrometric tactile thresholds was refined by Stenfeldt et al. [34]. Using this instrument, Jacobs et al. tested the vibrometric tactile thresholds in a group of patients with upper- or lower-limb OI prostheses and a control group with socket-suspended prostheses [35]. The study used frequencies of $8,16,32,64,125$, and $250 \mathrm{~Hz}$. These researchers found that the detection thresholds for vibratory stimulation of socket-suspended prosthetic limbs generally were higher than for nondisabled limbs, while OI prostheses yielded better perception than the socketsuspended prostheses. The authors suggested that the artificial limbs probably reduced the vibrometric signal [35]. There are, to our knowledge, no data available on how prosthetic components reduce vibrometric signals. Furthermore, there are no data available concerning the time course of the development of osseoperception in relation to implant insertion in patients with OI prostheses.

The aims of the present study were (1) to increase our knowledge regarding the detection level of vibrotactile stimulation in patients with transfemoral prostheses, (2) to report prospective data for the prosthetic and nondisabled limb in patients treated with unilateral transfemoral OI prostheses, (3) to compare the data with a group of controls using socket-suspended prostheses, and (4) to start to explore how vibrometric signals are absorbed/ reduced through a test prosthesis.

The overall hypothesis was that patients with OI prostheses should have improved ability to detect vibrations compared with their own preoperative situation with socket-suspended prostheses and also compared with other patients with socket-suspended prostheses. The hypothesis concerning the test prosthesis was that the prosthesis would influence the transmission of the vibrometric signal. 


\section{METHODS}

\section{Participants}

Two groups of patients were included in the current study: a group of patients having the osseointegration treatment and a group of controls. For both groups, the inclusion criteria were having a unilateral TFA for at least 2 yr from causes other than diabetes or arteriosclerosis, being between 20 and $65 \mathrm{yr}$ old, and being a prosthetic user. Patients with bone-anchored prostheses (OI group) should have been treated in Sweden and had their surgery performed between the years 1998 and 2007. In addition, patients in the OI group should have undergone the vibrometric measurements preoperatively with their socket-suspended prosthesis and at 2 yr follow-up with their OI prosthesis. The control group was selected from the group of patients from an earlier study [36], and participants were excluded if the reason for amputation was diabetes or arteriosclerosis.

The OI group included 17 patients ( 8 males and 9 females; mean age 44.6 yr [range: $23-63 \mathrm{yr}$ ]; mean time since amputation 14.5 yr [range: 2-42 yr]; cause of amputation: 11 trauma, 6 tumor). The control group included 17 patients (11 males and 6 females; mean age 43.2 yr [range: 29-63 yr]; mean time since amputation 18 yr [range: 2-34 yr]; cause of amputation: 11 trauma, 6 tumor). All patients in the control group had a prosthetic socket suspended by vacuum without any liner. Details of all prosthetic components are presented in Table 1. The classification of the type of prosthetic knee and foot components included in the prostheses at each assessment for all participants was done according to the classification proposed by REHAB Tech, Biomedical Engineering, Department of Electrical and Computer System Engineering, Monash University in Australia. A large number of patients in the OI group underwent changes of various prosthetic components between the two assessments. At follow-up, five patients had exactly the same type of prosthetic components as preoperatively and 12 had changed at least some of the components (Table 1) (5 changed foot, 5 changed to a more massive knee joint, 2 changed to a less massive knee joint, 5 added a shock absorber/torsion adapter). Most of the patients had a cosmetic cover (Table 1).

\section{Apparatus}

The test setup for the vibrometric evaluation is similar to a hearing test and replicates the one described by Stenfeldt et al. [34] and Jacobs et al. [35]. The hardware consists of a box, which contains a vibrating device, a response button, and a computer with the custom-designed Vibra98 software (Integrum AB; Gothenburg, Sweden). The command signal for the start of the assessment came

Table 1.

Prosthetic components. Prosthetic knee joints, foot component, shock absorber/torsion adapter, and cosmetic cover in osteointegrated (OI) group preoperatively and at $2 \mathrm{yr}$ follow-up and control group. Classification of prosthetic knee joint and prosthetic feet was made using system proposed by REHAB Tech, Biomedical Engineering, Department of Electrical and Computer System Engineering, Monash University in Australia.

\begin{tabular}{lccc}
\hline \multirow{2}{*}{ Component } & \multicolumn{2}{c}{ OI Group $(\boldsymbol{n}=\mathbf{1 7})$} & \multirow{2}{*}{ Control Group $(\boldsymbol{n}=\mathbf{1 7})$} \\
\cline { 2 - 3 } & Preoperative & 2 Yr Follow-Up & 9 \\
Prosthetic Knee Joint & 4 & 6 & 1 \\
Polycentric Cadence Responsive & 0 & 0 & 4 \\
Polycentric & 9 & 9 & 1 \\
Single-Axis Cadence Responsive & 0 & 2 & 2 \\
Single-Axis Friction & 4 & 0 & 7 \\
Single-Axis Stance Locking & & & 4 \\
Prosthetic Foot & 11 & 6 & 2 \\
Dynamic & 3 & 0 & 3 \\
Multiaxis & 0 & 3 & 1 \\
Solid Ankle Cushion Heel & 3 & 0 & $1 / 1$ \\
Single-Axis & 0 & $4 / 1$ & 16 \\
Syme & 0 & 15 & \\
Shock Absorber/Torsion Adapter & 16 & & \\
Cosmetic Cover & & & \\
\hline \hline
\end{tabular}


from the computer and was fed through a power amplifier located in the box connected to the device with a vibrator. The patient received stimulation under the intact and prosthetic foot through a pin extension (area $7 \mathrm{~mm}^{2}$ ) of a vibrator (model V4, Gearing and Watson Electronics Ltd; Hailsham, England), which produced a variable force to the vibrating pin. A force transducer (Dytran model 1051V1, Dynamic transducer and Systems; Chatsworth, California) was used to measure the force level delivered by the vibration unit.

\section{Measurement Procedure}

The measurement procedure was based on the experience from earlier tests [34-35]. The participant was seated comfortably in a chair in a quiet room. One foot at a time was placed on a box. Through a $50 \mathrm{~mm}^{2}$ hole in the box, a vibrating pin hit the foot at the location of the first metatarsal head (Figure 1). The skin (or cosmetic

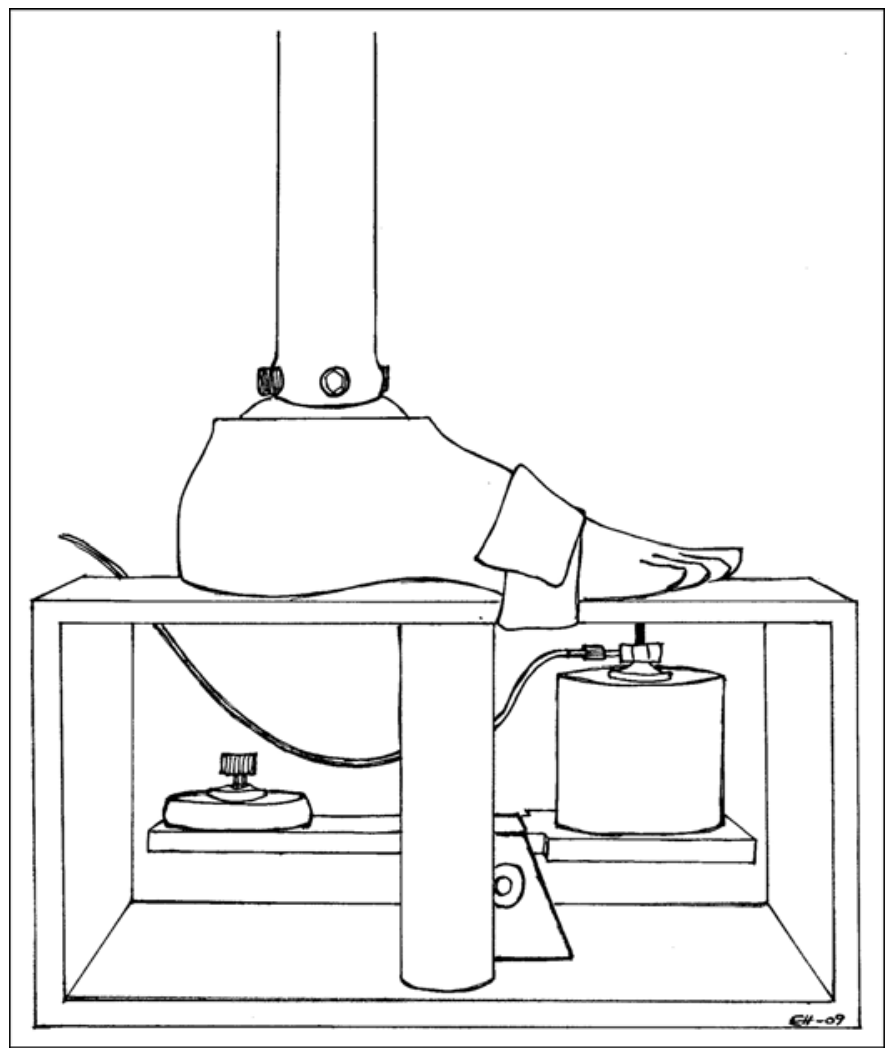

Figure 1.

Test setup for measurement of vibrometric signals through participants' intact and prosthetic feet. Extension pin from vibrator is hitting feet at location of first metatarsal head. cover of the prosthetic foot) touched the surrounding surface of the box, and the depth from the pin at the forefoot was $1 \mathrm{~mm}$. The participant operated the response button, and a software program controlled the order of the frequencies and the increase and decrease of the signal. When the measurement started, the amplitude from the vibrating pin started low and continuously increased. As soon as the participant could detect the vibration, he or she pressed the remote button. When the participant pressed the button, the amplitude began decreasing and the participant was asked to stop pressing the button as soon as the vibration was no longer noticed. Then the amplitude rose again when the patient let go of the response button and the procedure started all over again. The order of frequencies investigated was 32, 64, 125, 250, 8, 16, and $32 \mathrm{~Hz}$, and each frequency was rerun 16 times before the next was investigated. The order of the different frequencies was unknown by the participant but known by the examiner. The apparatus showed the amplitude in decibel/second. The step-size was set to $0.2 \mathrm{~dB} / \mathrm{s}$ and the range was 0 to $130 \mathrm{~dB}$. If no vibration was detected at $130 \mathrm{~dB}$, the system went into overload and the cycle was recorded as $130 \mathrm{~dB}$. A familiarizing trial was conducted before each assessment. The full assessment (both prosthetic and intact foot) lasted approximately $45 \mathrm{~min}$ and could be stopped at any time if the patient so required. Participants in the OI group were measured at two occasions: first preoperatively using their socketsuspended prosthesis and second at 2 yr after osseointegration treatment using their OI prosthesis. Participants in the control group, with socket-suspended prostheses, were measured once.

\section{Test Prosthesis}

To get an idea of the amount of absorption of vibrometric signals through a prosthesis, a copy of the prosthesis with the most numerous and massive components in the study group was built. This prosthesis was chosen since we hypothesized that a prosthesis including the largest number of interacting components most likely would reduce more of the vibrometric transmissions than a less massive prosthesis.

This experimental, or test, prosthesis was placed on the same box (Figure 2) and all test frequencies were measured at two locations: (1) at the prosthetic foot blade at the position of the first metatarsal head and (2) at the proximal medial socket edge. The points of measurement were chosen because a horizontal position of the sensor 


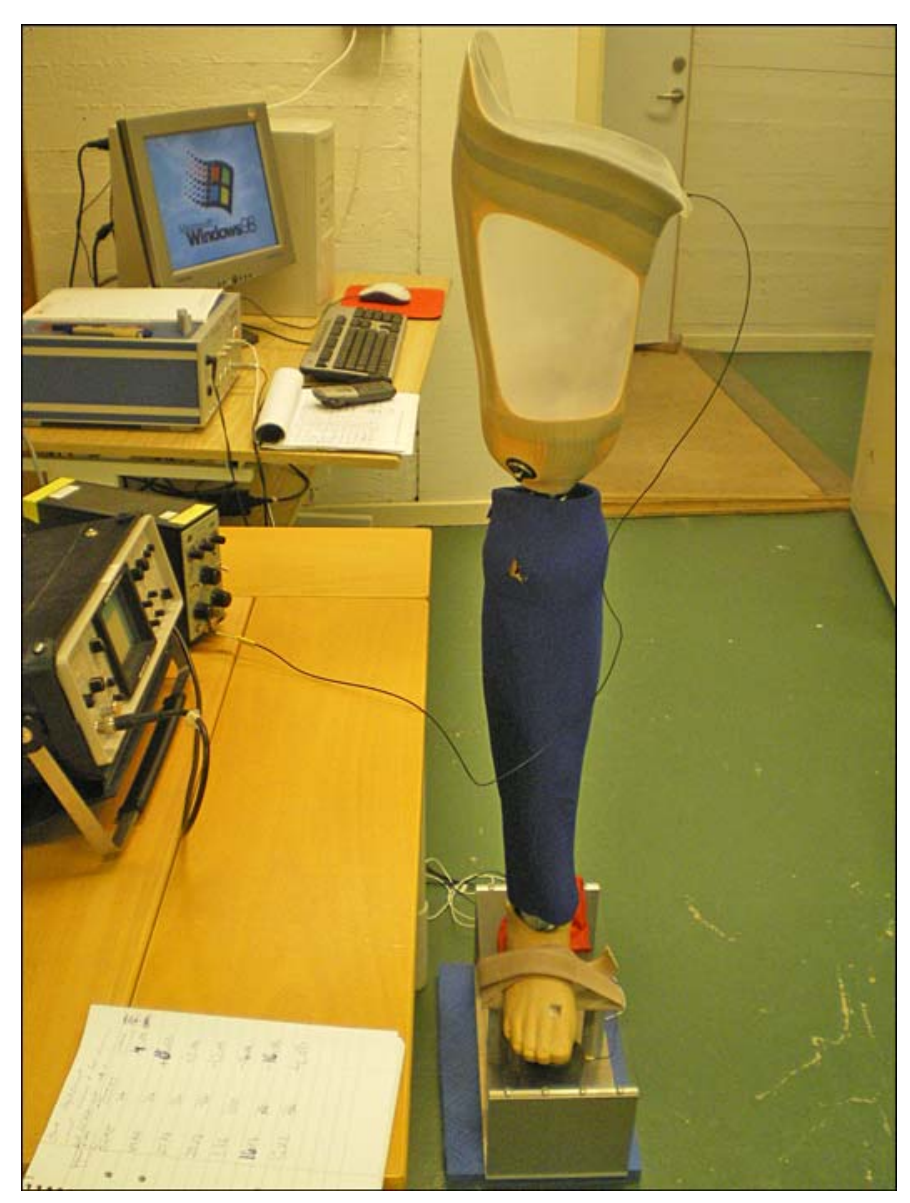

Figure 2.

Test of vibrometric signals through test prosthesis. Most massive socket-suspended prosthesis $(4.9 \mathrm{~kg})$ included in study was duplicated for test. It included ischial containment vacuum socket with thermoflex inside and laminated carbonfiber frame with built-in pyramid adapter, transversal adapter 4R57, Mauch knee joint, $30 \mathrm{~mm}$ tube, Ceterus standard prosthetic foot (category 7 with shock absorption combined with torsion adapter), and cosmetic cover distal part up to knee joint. Height from tuber ischii to heel was $100.5 \mathrm{~cm}$, height from medial socket edge to heel was $98 \mathrm{~cm}$, and height from center of knee to heel was $58 \mathrm{~cm}$. Foot size was $29 \mathrm{~cm}$.

was needed. The difference between the two values gave a value of the absorption of the vibrometric signal through the test prosthesis. The outcome was read when the signal from the power amplifier showed $115 \mathrm{~dB}$. The measurement equipment used was a sensor (4393, Brüel \& Kjær; Nærum, Denmark) and an amplifier accelerometer (Charge amplifier: Brüel \& Kjær, type 2635; Spectrum Analyzer: RION SA-24, Real Time Analyzer from RION
Co Ltd; Tokyo, Japan). To compare the results of absorption in the test prosthesis, an attenuation factor was calculated. This factor is used when comparing gradual loss of intensity or some kind of flux through a medium, for example, light or sound through water. An example of attenuating of vibrations is when different seat designs in cars are compared [37].

\section{Analysis and Statistical Methods}

The amplitude of the detection threshold for all tests was calculated after 16 cycles at each frequency (mean value in micronewtons). Since the apparatus showed the amplitude in decibels per second, the vibrotactile threshold was measured as a force level expressed in decibels $\left(\mathrm{F}_{\mathrm{dB}}\right)$ relative to micronewtons $\left(\mathrm{F}_{\mu \mathrm{N}}\right)$ using the formula $\mathrm{F}_{\mu \mathrm{N}}=10^{(\mathrm{FdB} / 20)} \times 10^{-6} \mathrm{~N}$.

The results are presented as mean and standard deviation for each frequency. The repeated measurements at $32 \mathrm{~Hz}$ are presented as a mean of the two cycles for each participant. For analyses of differences within groups, the Wilcoxon signed rank test was used. For analyses of differences between groups, the Mann-Whitney U-test was used. All tests were two-tailed and conducted at 5 percent significance level.

The accuracy of the assessment was determined by comparing the data obtained at the repeated measurements at $32 \mathrm{~Hz}$ (the first and last measurement within each assessment) using the intraclass coefficient (ICC) [38]. The ICC was calculated for all measurements, irrespective of group, on the prosthetic limb and the intact limb separately.

The results of the measurements conducted on the test prosthesis are presented as the difference between the two signals read at the proximal and distal part of the prosthesis. The difference is expressed in decibels. A negative and a positive numeral mean a reduction and a strengthening of the transmitted vibration, respectively. The attenuation factor "A" ("absorbing factor") is expressed with the formula: $A=(d B) 10^{(a / 20)}$, where "a" corresponds to the attenuation in decibels.

\section{RESULTS}

Results of the detection level of vibration signals for each frequency measured on the prosthetic and intact limbs for the OI and control groups are presented in Table 2. Table 3 presents all differences between measurements. 
Table 2.

Detection threshold of vibrotactile stimulation in prosthetic and intact limbs in frequencies between 8 and $250 \mathrm{~Hz}$. Sensitivity in prosthetic and intact limbs (in $\mu \mathrm{N}$ ) for 17 patients before osteointegrated (OI) treatment with socket-suspended prostheses and at 2 yr follow-up with OI prostheses and for 17 patients with socket-suspended prostheses (control group). Values are mean \pm standard deviation.

\begin{tabular}{|c|c|c|c|c|c|c|}
\hline \multirow{3}{*}{ Frequency $(\mathrm{Hz})$} & \multicolumn{4}{|c|}{ OI Group } & \multicolumn{2}{|c|}{ Control Group } \\
\hline & \multicolumn{2}{|c|}{$\begin{array}{c}\text { Preoperative } \\
\end{array}$} & \multicolumn{2}{|c|}{2 Yr Follow-Up } & \multirow{2}{*}{ Prosthetic Limb } & \multirow{2}{*}{ Intact Limb } \\
\hline & Prosthetic Limb & Intact Limb & Prosthetic Limb & Intact Limb & & \\
\hline 8 & $121.4 \pm 17.7$ & $102.4 \pm 14.8$ & $120.4 \pm 14.1$ & $98.9 \pm 11.2$ & $120.5 \pm 16.8$ & $105.4 \pm 17.2$ \\
\hline 16 & $115.4 \pm 13.0$ & $103.9 \pm 13.9$ & $114.6 \pm 16.9$ & $99.2 \pm 12.0$ & $123.0 \pm 10.6$ & $106.1 \pm 14.1$ \\
\hline 32 (Mean) & $108.4 \pm 13.8$ & $100.8 \pm 14.7$ & $108.5 \pm 10.9$ & $96.7 \pm 10.7$ & $112.8 \pm 11.0$ & $101.4 \pm 14.9$ \\
\hline 64 & $107.5 \pm 9.6$ & $95.1 \pm 12.7$ & $103.6 \pm 7.7$ & $91.5 \pm 10.3$ & $109.2 \pm 10.5$ & $97.8 \pm 14.2$ \\
\hline 125 & $110.0 \pm 13.4$ & $98.6 \pm 17.0$ & $100.7 \pm 13.8$ & $95.8 \pm 12.6$ & $113.7 \pm 15.8$ & $97.1 \pm 18.1$ \\
\hline 250 & $121.6 \pm 15.7$ & $111.6 \pm 16.3$ & $110.9 \pm 17.2$ & $104.8 \pm 13.1$ & $122.9 \pm 15.7$ & $109.0 \pm 16.9$ \\
\hline
\end{tabular}

The OI group showed a statistically significantly improved ability to detect the vibration at a frequency of $125 \mathrm{~Hz}$ on the prosthetic limb at 2 yr follow-up (mean difference $9.4 \mu \mathrm{N}, p=0.02$ ) (Table 3). Furthermore, the results showed that the OI group had better ability to detect high frequency vibrations $(125$ and $250 \mathrm{~Hz})$ in the prosthetic limb at follow-up than the control group ( $p=$ 0.01 and 0.03 , respectively) (Table 3). For most frequencies, in both groups, statistically significantly lower detection thresholds were found for the intact limb.

The ICC of the first and last frequency at $32 \mathrm{~Hz}$ was 0.83 for the prosthetic limb and 0.79 for the intact limb.

Results illustrating the transmission of vibrometric signals through the test prosthesis (Figure 2) are pre- sented in Table 4. The differences in transmitted vibrations were between $-16 \mathrm{~dB}$ and $+12 \mathrm{~dB}$ depending on the frequency measured. The signal was reduced in the frequencies 8, 125, and $250 \mathrm{~Hz}$ and amplified in the frequencies 16, 32, and $64 \mathrm{~Hz}$.

\section{DISCUSSION}

This is the first study evaluating osseoperception before and after osseointegration treatment in patients with a TFA. The main findings are that the OI prosthetic connection seems to improve the patients' ability to detect vibrotactile stimuli of higher frequencies applied

Table 3.

Differences of detection threshold of vibrotactile stimulation.

\begin{tabular}{|c|c|c|c|c|c|c|c|c|c|}
\hline \multirow{3}{*}{$\begin{array}{c}\text { Frequency } \\
\text { (Hz) }\end{array}$} & \multicolumn{6}{|c|}{ OI Preop vs 2 Yr Follow-Up } & \multicolumn{3}{|c|}{$\begin{array}{l}\text { OI Group Preop Prosthetic } \\
\text { vs Intact Limb }\end{array}$} \\
\hline & \multicolumn{3}{|c|}{ Prosthetic Limb } & \multicolumn{3}{|c|}{ Intact Limb } & \multirow{2}{*}{$\begin{array}{c}\text { Mean } \pm \text { SD } \\
\quad(\mu N)\end{array}$} & \multirow{2}{*}{$\begin{array}{c}\text { Det/Imp/Tie } \\
\text { (n) }\end{array}$} & \multirow{2}{*}{$p$-Value } \\
\hline & $\begin{array}{c}\text { Mean } \pm \text { SD } \\
(\mu N)\end{array}$ & $\begin{array}{c}\text { Det/Imp/Tie } \\
\text { (n) }\end{array}$ & $\overline{p \text {-Value }}$ & $\begin{array}{c}\operatorname{Mean} \pm \text { SD } \\
(\mu N)\end{array}$ & $\begin{array}{c}\text { Det } / \text { Imp/Tie } \\
(n)\end{array}$ & $p$-Value & & & \\
\hline 8 & $1.0 \pm 11.6$ & $3 / 3 / 11$ & 0.92 & $-0.6 \pm 8.72$ & $8 / 8 / 1$ & 0.68 & $-22.0 \pm 18.8$ & $1 / 12 / 4$ & 0.002 \\
\hline 16 & $1.6 \pm 17.9$ & $6 / 7 / 4$ & 0.92 & $2.6 \pm 9.4$ & $5 / 11 / 1$ & 0.16 & $-13.6 \pm 18.0$ & $1 / 12 / 4$ & 0.01 \\
\hline 32 (Mean) & $-0.1 \pm 9.51$ & $5 / 11 / 1$ & 0.64 & $3.4 \pm 15.6$ & $7 / 10 / 0$ & 0.19 & $-8.3 \pm 18.8$ & $4 / 13 / 0$ & 0.07 \\
\hline 64 & $-3.9 \pm 13.5$ & $10 / 7 / 0$ & 0.59 & $1.0 \pm 12.3$ & $7 / 10 / 0$ & 0.59 & $-15.1 \pm 12.9$ & $2 / 15 / 0$ & 0.001 \\
\hline 125 & $9.4 \pm 15.5$ & $3 / 13 / 1$ & 0.02 & $4.2 \pm 16.0$ & $7 / 10 / 0$ & 0.36 & $-10.0 \pm 17.5$ & $2 / 12 / 3$ & 0.003 \\
\hline 250 & $10.7 \pm 20.3$ & $3 / 8 / 6$ & 0.08 & $9.5 \pm 16.3$ & $3 / 11 / 3$ & 0.07 & $-7.4 \pm 21.3$ & $3 / 6 / 8$ & 0.21 \\
\hline
\end{tabular}

Note: Results of comparisons within groups are noted as "Det," “Imp," or “Tie,” meaning how many results were lower, higher, or same when comparing OI Det $=$ deteriorated, Imp = improved, $\mathrm{OI}=$ osseointegrated, Preop = preoperative, $\mathrm{SD}=$ standard deviation. 
under the prosthetic foot. At 2 yr follow-up, the OI group showed a lower detection threshold at $125 \mathrm{~Hz}$ than in the preoperative measurement. Moreover, at follow-up the OI group had a lower detection threshold than the group of controls at both 125 and $250 \mathrm{~Hz}$ (Table 3). The improved osseoperception might help to explain why patients with OI prostheses have reported their prosthesis to become "as a part of me" [15], and the result adds to the published benefits of OI prosthesis [10,39-41]. Another main finding was that vibrometric signals tested through a test prosthesis not only reduced the vibrometric signals at 8,125 , and $250 \mathrm{~Hz}$ but also amplified the vibration at 16, 32, and $64 \mathrm{~Hz}$ (Table 4).

Although patient groups were not matched, most aspects of patient demographics were similar in the two groups. However, it should be noted that there was a difference in sex distribution, with more females in the OI group than the control group. The results showed no statistically significant differences of detection level of signals when the prosthetic limb was compared between the preoperative measurement in the OI group and the control group (both with socket-suspended prostheses) (Table 3). Furthermore, no differences were found when comparing the intact limb between groups (Table 3). Altogether, these findings show the groups to be comparable.

The study included some limitations. One is the relatively low number of patients included. However, the 17 patients in the OI group represented more than 10 percent of the existing population of patients treated with TFA OI prostheses worldwide at the time of the study [9-10]. Moreover, the number of participants is comparable to other studies in the prosthetic and orthotic field [35,3940,42-43]. Because of practical considerations, the test was performed in a sitting position. We found it difficult for this group of patients to accomplish the test while standing (>30 min) and having to concentrate on the vibrometric sensations and press a response button. It is not known if the sitting posture in contrast to a standing posture might have influenced the results. The single occasion measurement in the control group was a limitation; this prevented analyses of changes of the ability to detect vibration over time in patients using socketsuspended prostheses. Another limitation was the large variation of prosthetic components and the fact that many patients in the OI group had changed components between measurements (Table 1), which probably affected the results. In a few cases, a shock absorber or a torsion adapter had been added to the OI prosthesis at follow-up (Table 1). Those components are designed to reduce forces at heel strike and to reduce rotational forces, respectively, and hypothetically would reduce vibrations. However, 10 patients in the OI group had the same knee components at both assessments (Table 1). Change of components in OI prostheses is usually done between 6 and 12 mo after the OI treatment when the patients can put full weight-bearing on the prosthesis [9].

Table 3. (Continued from across left page)

Differences of detection threshold of vibrotactile stimulation.

\begin{tabular}{|c|c|c|c|c|c|c|c|c|c|}
\hline \multicolumn{3}{|c|}{$\begin{array}{l}\text { OI Group } 2 \text { Yr Follow-Up } \\
\text { Prosthetic vs Intact Limb }\end{array}$} & \multicolumn{3}{|c|}{$\begin{array}{c}\text { Control Group Prosthetic } \\
\text { vs Intact Limb }\end{array}$} & \multicolumn{2}{|c|}{$\begin{array}{l}\text { Control vs OI Preop } \\
p \text {-Value }\end{array}$} & \multicolumn{2}{|c|}{$\begin{array}{l}\text { Control vs OI } 2 \text { Yr } \\
\text { Follow-Up p-Value }\end{array}$} \\
\hline $\begin{array}{c}\text { Mean } \pm \text { SD } \\
(\mu N)\end{array}$ & $\begin{array}{c}\text { Det/Imp/Tie } \\
\text { (n) }\end{array}$ & $p$-Value & $\begin{array}{c}\text { Mean } \pm \text { SD } \\
(\mu N)\end{array}$ & $\begin{array}{c}\text { Det/Imp/Tie } \\
\text { (n) }\end{array}$ & $p$-Value & $\begin{array}{l}\text { Prosthetic } \\
\text { Limb }\end{array}$ & $\begin{array}{l}\text { Intact } \\
\text { Limb }\end{array}$ & $\begin{array}{l}\text { Prosthetic } \\
\text { Limb }\end{array}$ & $\begin{array}{l}\text { Intact } \\
\text { Limb }\end{array}$ \\
\hline & $0 / 14 / 3$ & 0.001 & $-15.2 \pm 18.9$ & $2 / 10 / 5$ & 0.01 & 0.74 & 0.38 & 0.79 & 0.23 \\
\hline \multirow[t]{2}{*}{$-15.4 \pm 13.7$} & $1 / 14 / 2$ & 0.001 & $-17.0 \pm 15.6$ & $1 / 13 / 3$ & 0.002 & 0.08 & 0.39 & 0.10 & 0.15 \\
\hline & $4 / 13 / 0$ & 0.004 & $-11.4 \pm 12.0$ & $1 / 14 / 2$ & 0.01 & 0.65 & 0.88 & 0.28 & 0.50 \\
\hline$-12.1 \pm 9.2$ & $2 / 15 / 0$ & 0.001 & $-11.4 \pm 10.2$ & $1 / 14 / 2$ & 0.001 & 0.74 & 0.40 & 0.44 & 0.26 \\
\hline$-4.9 \pm 9.6$ & $6 / 9 / 2$ & 0.047 & $-16.5 \pm 21.9$ & 2/12/3 & 0.01 & 0.49 & 0.52 & 0.01 & 0.99 \\
\hline$-6.2 \pm 12.5$ & $4 / 8 / 5$ & 0.10 & $-13.9 \pm 20.3$ & $2 / 11 / 4$ & 0.04 & 0.85 & 0.54 & 0.03 & 0.32 \\
\hline
\end{tabular}

preoperatively with OI 2 yr follow-up. 
Table 4.

Result of absorption of the vibrometric signal through transfemoral test prosthesis.

\begin{tabular}{lcccc}
\hline Frequency (Hz) & Socket Edge (dB) & Footblade (dB) & Difference (dB) & $\begin{array}{c}\text { Result, Attenuation Factor/ } \\
\text { Absorption Factor }\end{array}$ \\
\hline 8 & -26 & -22 & -4 & 0.6 (Reduction) \\
16 & -16 & -20 & +4 & 1.6 (Strengthening) \\
32 & -4 & -16 & +12 & 4.0 (Strengthening) \\
64 & 8 & 2 & +6 & 2.0 (Strengthening) \\
125 & 2 & 8 & -6 & 0.5 (Reduction) \\
250 & -12 & 4 & -16 & 0.2 (Reduction) \\
\hline
\end{tabular}

Note: Readings at medial edge of prosthetic socket and at prosthetic foot blade at $115 \mathrm{~dB} / \mu \mathrm{N}$ out-signal from amplifier accelerometer. Result shows difference between two readings, and attenuation factor ("absorbing factor") is reported as reduction/dampening or strengthening/amplifying of vibration signal through testprosthesis. Attenuation factor $\mathrm{A}$ is expressed as: $\mathrm{A}=(\mathrm{dB}) 10^{(\mathrm{a} / 20)}$; "a" corresponds to attenuation in $\mathrm{dB}$.

The scope of the current study was not to conduct vibrometric measurement on all prosthetic components or all combinations of components, and we encourage future studies in this area.

Finally, there was no randomization of the order of the frequencies tested between trials. However, since the frequencies were not in a numerical order of size, there is no reason to believe the OI patients would remember the order of frequencies $2 \mathrm{yr}$ later at the second test.

The method of evaluation used was similar to the QST method of limits Claus et al. used [26], with the patient answering with a response button when vibrometric stimuli could be detected or not detected anymore. The method was chosen because it provides some comparable measurements to previous work [35]. The objectivity of the method of measuring sensitivity has been questioned by Freeman et al., who proposed that subjects can deceive the examiner [44]. On the other hand, Chong and Cros concluded that the reliability is highly dependent on accurate use of methodology [23]. In the current study, the first and last measurement of each trial was made at the same frequency $(32 \mathrm{~Hz})$ to test the accuracy. The results showed the reliability to be satisfactory since the ICC of the repeated measurement was above the adequate level of 0.70 for group comparisons [38], both when analyzed for the prosthetic limb (ICC $=0.83$ ) and the intact limb (ICC $=0.79$ ).

Most research on perception has used different evaluation methods and equipment and has been performed on different groups of patients, making comparisons to the current results difficult. Lundborg et al. used equipment comparable to the apparatus in the present study and used similar frequencies to assess the vibrotactile thresholds in the pulp of the index and little fingers in subjects with diverse diagnoses in the upper limb compared to an age- matched reference population [29]. The mean values among the reference population were in the range between 100 and $120 \mu \mathrm{N}$ in the frequencies 32.5, 65, 125, and $250 \mathrm{~Hz}$. Our values in the same frequencies were between 104 and $111 \mu \mathrm{N}$ for OI prostheses, 108 and 123 $\mu \mathrm{N}$ for socket-suspended prostheses, and 95 and $112 \mu \mathrm{N}$ for the intact limb (Table 2). Aaserud et al. showed higher vibrometric thresholds on the upper than the lower limb in a study assessing 12 nondisabled subjects [30]. The results from Aaserud et al. could explain why our values for the intact limb were somewhat lower than those reported by Lundborg et al. [29].

The only study in which results more directly can be compared with the results of the present study was conducted by Jacobs et al. [35]. In that study, patients with socket-suspended upper- and lower-limb prostheses showed an average of 20 percent higher detection levels on the prosthetic side than on the intact side. The results are comparable to our control group, which showed 11 to 17 percent higher thresholds in the prosthetic limb than in the intact limb (Tables 2 and 3). The same authors also proposed that the most important factor decreasing the signal would be the prosthetic components [35]. Participants in the current study had a large variation of prosthetic components (Table 1), and within the OI group many had changed some part of their prostheses between the assessments. We agree that the prosthetic components can have important implications on the results. This was one of the reasons why we conducted measurements on a test prosthesis. The results from the test prosthesis showed that the vibration signal was dampened in some frequencies $(8,125$, and $250 \mathrm{~Hz})$ but, surprisingly, amplified at others (16, 32, and $64 \mathrm{~Hz}$ ) (Table 4). This varying result could be due to the different parts of the prosthesis, which might give rise to self-oscillation or resonance 
amplification. An amplification of the vibrometric signals occurred at the middle frequencies $(16,32,64 \mathrm{~Hz})$ and a dampening of the vibrometric signal at the highest (125 and $250 \mathrm{~Hz}$ ) and the lowest $(8 \mathrm{~Hz})$ frequency. There is no simple explanation for this behavior and it is important to emphasize that the results presented for the test prosthesis should only be considered as a result of how a single representative prosthesis attenuates the tested vibrations. The transmission of vibration through the different components will depend on, for instance, stiffness and dampening factors in the components as well as in the boundaries between the components. Why the highest and the lowest frequency resulted in absorption of vibration instead of resonance and whether the choice of prosthesis tested influenced the result cannot be answered in the current study, and further studies are needed to resolve this issue. It should also be noted that the test prosthesis was not attached at the proximal end. If the prosthesis had been fitted to a patient and a residual limb had been placed into the socket, the prosthesis would probably have been less inclined to resonance behavior. Therefore, the result of the test prosthesis should be read with the consideration that the lack of proximal attachment might have affected the self-oscillation. Moreover, it is unknown how an individual residual limb and socket fit might influence the outcome in the vibrometric measurements.

In the current study, the statistically significantly lower detection levels were all shown in the higher frequencies (Table 3) and were shown in the same frequencies in which signals transmitted through the test prosthesis were reduced (at $125 \mathrm{~Hz}$ with $-6 \mathrm{~dB}$ and at $250 \mathrm{~Hz}$ with $-16 \mathrm{~dB}$, Table 4). If the results of the test prosthesis, with dampened signals in higher frequencies, correspond to the behavior of the prostheses in the study groups, it means the OI group could detect the dampened vibrations better at $2 \mathrm{yr}$ follow-up.

The statistically significant improvements were found in the higher frequencies. There is, however, no information available on which frequencies are more important to detect, nor do we know which detection level is of clinical importance. We can only conclude that the OI group at $2 \mathrm{yr}$ follow-up could detect a few more frequencies better through their prostheses than before OI treatment and than the control group. Safe walking and fear of falling are important issues for a majority of patients with lower-limb amputations [45-46]. Because of the loss of the knee joint, patients with TFA need strat- egies to maintain balance and to overcome limitations in function of the prosthesis [31-32]. A safe and secure gait and confidence in walking can partly be achieved by training and adequate prosthetic fit and suspension. The decreased sensory feedback through the prosthesis as compared with the intact limb can be a limiting factor in this regard. We suggest that a better ability to detect vibration through the prosthesis at heel strike can give the patient additional feedback of the position of the prosthetic foot and knee. Whether increased sensibility from under the prosthetic foot can prevent falling is not a question the current study can answer, but we believe the more feedback a patient can get for safety, the better. The literature so far presents no evidence of the relationship between less incidence of fall and improved osseoperception. Hypothetically, it can be expected that the firm connection with OI prostheses is advantageous compared with conventional socket-suspended prostheses, resulting in improved stumbling control and less falling.

\section{CONCLUSIONS}

The results of this study showed that patients with TFA using OI prostheses have an improved detection threshold for high-frequency vibratory stimulations applied under the prosthetic foot. Furthermore, vibrations transferred through a test prosthesis were found to be decreased or amplified depending on the frequency of the vibration. Feedback of high frequency vibrations from the surroundings through the prosthetic components have in this study been shown to be more easily recognized by patients treated with OI amputation prostheses as compared with conventional socket prostheses, potentially leading to advantages in gait control for patients with an OI prosthesis.

\section{ACKNOWLEDGMENTS}

\section{Author Contribution:}

Study concept and design: B. Rydevik, R. Brånemark, K. Hagberg, E. Häggström.

Acquisition of data: K. Hagberg, E. Häggström.

Analysis and interpretation of data: E. Häggström.

Drafting of manuscript: E. Häggström.

Critical revision of manuscript for important intellectual content:

B. Rydevik, R. Brånemark, K. Hagberg, E. Häggström.

Statistical analysis: E. Häggström. 
Administrative, technical, or material support: B. Rydevik, R. Brånemark, K. Hagberg.

Study supervision: B. Rydevik, R. Brånemark, K. Hagberg.

Financial Disclosures: Rickard Brånemark, MD, has commercial associations (stock ownership in Integram $\mathrm{AB}$ ) that might pose a conflict of interest in connection with the article.

Funding/Support. This material was based on work supported by ALF/LUA at the Sahlgrenska University Hospital, Dr Felix Neubergh Research Foundation, Gothenburg, Sweden, and Stiftelsen Promobilia, Sweden (grants ALF GBG 11128 and ALF GBG 138 721).

Additional Contributions: The authors would like to thank Professor Laurent Frossard, University of Montreal, Montreal, Canada, for help and insightful comments to the text; Per Jonsson, PhD, Occupational and Environmental Medicine at Sahlgrenska University Hospital, Gothenburg, Sweden, for valuable advice regarding measurement of vibrations; and Hanna Berander, CPO, and Stewe Jonsson, (at the time) $\mathrm{CPO}$, at the Department of Prosthetics and Orthotics, Sahlgrenska University Hospital, Gothenburg, Sweden, for help with conducting the measurements.

Institutional Review: The study was approved by the Research Ethic Committee at the University of Gothenburg, Sweden. All participants provided informed consent.

Participant Follow-Up: Participants were informed that the results would be published in a scientific journal.

\section{REFERENCES}

1. Brånemark R, Brånemark PI, Rydevik B, Myers RR. Osseointegration in skeletal reconstruction and rehabilitation: A review. J Rehabil Res Dev. 2001;38(2):175-81. [PMID:11392650]

2. Brånemark PI, Hansson BO, Adell R, Breine U, Lindström J, Hallén O, Ohman A. Osseointegrated implants in the treatment of the edentulous jaw. Experience from a 10-year period. Scand J Plast Reconstr Surg Suppl. 1977;16:1-132. [PMID:356184]

3. Albrektsson T, Brånemark PI, Hansson HA, Lindström J. Osseointegrated titanium implants. Requirements for ensuring a long-lasting, direct bone-to-implant anchorage in man. Acta Orthop Scand. 1981;52(2):155-70.

[PMID:7246093]

http://dx.doi.org/10.3109/17453678108991776

4. Brånemark PI, Adell R, Breine U, Hansson BO, Lindström J, Ohlsson A. Intra-osseous anchorage of dental prostheses. I. Experimental studies. Scand J Plast Reconstr Surg. 1969; 3(2):81-100. [PMID:4924041] http://dx.doi.org/10.3109/02844316909036699

5. Adell R, Lekholm U, Rockler B, Brånemark PI. A 15-year study of osseointegrated implants in the treatment of the edentulous jaw. Int J Oral Surg. 1981;10(6):387-416.

[PMID:6809663]

http://dx.doi.org/10.1016/S0300-9785(81)80077-4
6. Granström G. Craniofacial osseointegration. Oral Dis. 2007;13(3):261-69. [PMID:17448206] http://dx.doi.org/10.1111/j.1601-0825.2007.01365.x

7. Parel SM, Branemark PI, Tjellstrom A, Gion G. Osseointegration in maxillofacial prosthetics. Part II: Extraoral applications. J Prosthet Dent. 1986;55(5):600-6. [PMID:3458911] http://dx.doi.org/10.1016/0022-3913(86)90040-5

8. Granström G, Bergström K, Odersjö M, Tjellström A. Osseointegrated implants in children: Experience from our first 100 patients. Otolaryngol Head Neck Surg. 2001;125(1): 85-92. [PMID:11458220]

http://dx.doi.org/10.1067/mhn.2001.116190

9. Hagberg K, Brånemark R. One hundred patients treated with osseointegrated transfemoral amputation prosthesesrehabilitation perspective. J Rehabil Res Dev. 2009;46(3): 331-44. [PMID:19675986] http://dx.doi.org/10.1682/JRRD.2008.06.0080

10. Sullivan J, Uden M, Robinson KP, Sooriakumaran S. Rehabilitation of the trans-femoral amputee with an osseointegrated prosthesis: The United Kingdom experience. Prosthet Orthot Int. 2003;27(2):114-20. [PMID:14571941] http://dx.doi.org/10.1080/03093640308726667

11. Jönsson S, Caine-Winterberger K, Brånemark R. Osseointegration amputation prostheses on the upper limbs: methods, prosthetics and rehabilitation. Prosthet Orthot Int. 2011;35(2):190-200. [PMID:21697201]

http://dx.doi.org/10.1177/0309364611409003

12. Rydevik B, Shubayev V, Myers R. Osseoperception. In: Brånemark PI, editor. The osseointegration book: From calvarium to calcaneus. Chicago (IL): Quintessence; 2005. p. 149-55.

13. Klineberg I, Calford MB, Dreher B, Henry P, Macefield V, Miles T, Rowe M, Sessle B, Trulsson M. A consensus statement on osseoperception. Clin Exp Pharmacol Physiol. 2005;32(1-2):145-46. [PMID:15730451] http://dx.doi.org/10.1111/j.1440-1681.2005.04144.x

14. Hagberg K, Häggström E, Jönsson S, Rydevik B, Brånemark R. Osseoperception and osseointegrated prosthetic limbs. In: Gallagher P, Desmond D, MacLachlan M. Psychoprosthetics. London (United Kingdom): Springer; 2008. p. 131-40.

15. Lundberg M, Hagberg K, Bullington J. My prosthesis as a part of me: A qualitative analysis of living with an osseointegrated prosthetic limb. Prosthet Orthot Int. 2011;35(2): 207-14. [PMID:21697203] http://dx.doi.org/10.1177/0309364611409795

16. Jacobs R, Van Steenberghe D. From osseoperception to implant-mediated sensory-motor interactions and related clinical implications. J Oral Rehabil. 2006;33(4):282-92. [PMID:16629883] http://dx.doi.org/10.1111/j.1365-2842.2006.01621.x 
17. Klineberg I, Murray G. Osseoperception: Sensory function and proprioception. Adv Dent Res. 1999;13:120-29.

[PMID:11276734]

http://dx.doi.org/10.1177/08959374990130010101

18. van Steenberghe D. From osseointegration to osseoperception. J Dent Res. 2000;79(11):1833-37. [PMID:11145351] http://dx.doi.org/10.1177/00220345000790110301

19. Swinnen A, Van Huffel S, Van Loven K, Jacobs R. Detection and multichannel SVD-based filtering of trigeminal somatosensory evoked potentials. Med Biol Eng Comput. 2000;38(3):297-305. [PMID:10912346]

http://dx.doi.org/10.1007/BF02347050

20. Van Loven K, Jacobs R, Van Hees J, Van Huffel S, van Steenberghe D. Trigeminal somatosensory evoked potentials in humans. Electromyogr Clin Neurophysiol. 2001;41(6): 357-75. [PMID:11680861]

21. Lundborg G, Waites A, Björkman A, Rosén B, Larsson EM. Functional magnetic resonance imaging shows cortical activation on sensory stimulation of an osseointegrated prosthetic thumb. Scand J Plast Reconstr Surg Hand Surg. 2006;40(4):234-39. [PMID:16911998]

http://dx.doi.org/10.1080/02844310600787005

22. Ysander M, Brånemark R, Olmarker K, Myers RR. Intramedullary osseointegration: Development of a rodent model and study of histology and neuropeptide changes around titanium implants. J Rehabil Res Dev. 2001;38(2): 183-90. [PMID:11392651]

23. Chong PS, Cros DP. Technology literature review: Quantitative sensory testing. Muscle Nerve. 2004;29(5):734-47. [PMID:15116380] http://dx.doi.org/10.1002/mus.20053

24. Yarnitsky D, Sprecher E. Thermal testing: Normative data and repeatability for various test algorithms. J Neurol Sci. 1994;125(1):39-45. [PMID:7964887] http://dx.doi.org/10.1016/0022-510X(94)90239-9

25. Dyck PJ, Zimmerman IR, O’Brien PC, Ness A, Caskey PE, Karnes J, Bushek W. Introduction of automated systems to evaluate touch-pressure, vibration, and thermal cutaneous sensation in man. Ann Neurol. 1978;4(6):502-10.

[PMID:742850]

http://dx.doi.org/10.1002/ana.410040605

26. Claus D, Mustafa C, Vogel W, Herz M, Neundörfer B. Assessment of diabetic neuropathy: Definition of norm and discrimination of abnormal nerve function. Muscle Nerve. 1993;16(7):757-68. [PMID:8505932] http://dx.doi.org/10.1002/mus.880160711

27. Dargahi J, Najarian S. Human tactile perception as a standard for artificial tactile sensing-a review. Int J Med Robot. 2004;1(1):23-35. [PMID:17520594] http://dx.doi.org/10.1002/rcs.3

28. Vinik AI, Suwanwalaikorn S, Stansberry KB, Holland MT, McNitt PM, Colen LE. Quantitative measurement of cuta- neous perception in diabetic neuropathy. Muscle Nerve. 1995;18(6):574-84. [PMID:7753119]

http://dx.doi.org/10.1002/mus.880180603

29. Lundborg G, Dahlin LB, Lundström R, Necking LE, Strömberg T. Vibrotactile function of the hand in compression and vibration-induced neuropathy. Sensibility indexa new measure. Scand J Plast Reconstr Surg Hand Surg. 1992;26(3):275-79. [PMID:1335164] http://dx.doi.org/10.3109/02844319209015271

30. Aaserud O, Juntunen J, Matikainen E. Vibration sensitivity thresholds: Methodological considerations. Acta Neurol Scand. 1990;82(4):277-83. [PMID:2270757] http://dx.doi.org/10.1111/j.1600-0404.1990.tb01619.x

31. Vrieling AH, van Keeken HG, Schoppen T, Otten E, Halbertsma JP, Hof AL, Postema K. Gait initiation in lower limb amputees. Gait Posture. 2008;27(3):423-30.

[PMID:17624782]

http://dx.doi.org/10.1016/j.gaitpost.2007.05.013

32. Vrieling AH, van Keeken HG, Schoppen T, Otten E, Halbertsma JP, Hof AL, Postema K. Gait termination in lower limb amputees. Gait Posture. 2008;27(1):82-90.

[PMID:17376689]

http://dx.doi.org/10.1016/j.gaitpost.2007.02.004

33. Vrieling AH, van Keeken HG, Schoppen T, Otten E, Halbertsma JP, Hof AL, Postema K. Uphill and downhill walking in unilateral lower limb amputees. Gait Posture. 2008;28(2):235-42. [PMID:18242995]

http://dx.doi.org/10.1016/j.gaitpost.2007.12.006

34. Stenfeldt S, Jacobs R, Olmarker K, Rydevik B, Brånemark PI. A technique for determination of vibrotactile force threshold levels in patients with orthopaedic osseointegrated implants. In: Stenfelt S, editor. Biomechanical investigations with emphasis on bone conducted sound. Technical report No. 233L. Göteborg (Sweden): Bibliotekets Reproservice, Chalmers University of Technology; 1996.

35. Jacobs R, Brånemark R, Olmarker K, Rydevik B, Van Steenberghe D, Brånemark PI. Evaluation of the psychophysical detection threshold level for vibrotactile and pressure stimulation of prosthetic limbs using bone anchorage or soft tissue support. Prosthet Orthot Int. 2000;24(2):133-42. [PMID:11061200]

http://dx.doi.org/10.1080/03093640008726536

36. Hagberg K, Brånemark R, Hägg O. Questionnaire for Persons with a Transfemoral Amputation (Q-TFA): Initial validity and reliability of a new outcome measure. J Rehabil Res Dev. 2004;41(5):695-706. [PMID:15558399] http://dx.doi.org/10.1682/JRRD.2003.11.0167

37. Wijaya AR, Jönsson P, Johansson O. The effect of seat design on vibration comfort. Int J Occup Saf Ergon. 2003;9(2):193-210. [PMID:12820908] 
38. Shrout PE, Fleiss JL. Intraclass correlations: Uses in assessing rater reliability. Psychol Bull. 1979;86(2):420-28. [PMID:18839484] http://dx.doi.org/10.1037/0033-2909.86.2.420

39. Frossard L, Hagberg K, Häggström E, Lee D, Branemark R, Percy M. Functional outcome of transfemoral amputees fitted with an osseointegrated fixation: Temporal gait characteristics. J Prosthet Orthot. 2010;22:11-20. http://dx.doi.org/10.1097/JPO.0b013e3181ccc53d

40. Hagberg K, Häggström E, Uden M, Brånemark R. Socket versus bone-anchored trans-femoral prostheses: Hip range of motion and sitting comfort. Prosthet Orthot Int. 2005; 29(2):153-63. [PMID:16281724] http://dx.doi.org/10.1080/03093640500238014

41. Hagberg K, Brånemark R, Gunterberg B, Rydevik B. Osseointegrated trans-femoral amputation prostheses: Prospective results of general and condition-specific quality of life in 18 patients at 2-year follow-up. Prosthet Orthot Int. 2008;32(1):29-41. [PMID:18330803] http://dx.doi.org/10.1080/03093640701553922

42. Lee WC, Frossard LA, Hagberg K, Haggstrom E, Gow DL, Gray S, Brånemark R. Magnitude and variability of loading on the osseointegrated implant of transfemoral amputees during walking. Med Eng Phys. 2008;30(7):825-33. [PMID:17977050] http://dx.doi.org/10.1016/j.medengphy.2007.09.003

43. Rabuffetti M, Recalcati M, Ferrarin M. Trans-femoral amputee gait: Socket-pelvis constraints and compensation strategies. Prosthet Orthot Int. 2005;29(2):183-92. [PMID:16281727] http://dx.doi.org/10.1080/03093640500217182
44. Freeman R, Chase KP, Risk MR. Quantitative sensory testing cannot differentiate simulated sensory loss from sensory neuropathy. Neurology. 2003;60(3):465-70.

[PMID:12578928]

http://dx.doi.org/10.1212/WNL.60.3.465

45. Miller WC, Deathe AB, Speechley M, Koval J. The influence of falling, fear of falling, and balance confidence on prosthetic mobility and social activity among individuals with a lower extremity amputation. Arch Phys Med Rehabil. 2001;82(9):1238-44. [PMID:11552197] http://dx.doi.org/10.1053/apmr.2001.25079

46. Miller WC, Speechley M, Deathe B. The prevalence and risk factors of falling and fear of falling among lower extremity amputees. Arch Phys Med Rehabil. 2001;82(8): 1031-37. [PMID:11494181] http://dx.doi.org/10.1053/apmr.2001.24295

Submitted for publication August 1, 2012. Accepted in revised form June 18, 2013.

This article and any supplementary material should be cited as follows:

Häggström E, Hagberg K, Rydevik B, Brånemark R. Vibrotactile evaluation: Osseointegrated versus socketsuspended transfemoral prostheses. J Rehabil Res Dev. 2013;50(10):1423-34.

http://dx.doi.org/10.1682/JRRD.2012.08.0135

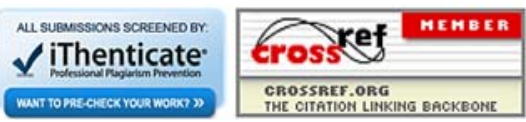

